\title{
ASO Visual Abstract: The Impact of Histological Liver Inflammation on Oncology and the Prognosis of Patients Undergoing Hepatectomy for Hepatocellular Carcinoma
}

Tatsunori Miyata, MD, PhD ${ }^{1}$, Hiromitsu Hayashi, MD, $\mathbf{P h D}^{1}$, Yo-ichi Yamashita, MD, $\mathbf{P h D}^{1}$, Kazuki Matsumura, $\mathrm{MD}^{1}$, Takaaki Higashi, $\mathrm{MD}, \mathrm{PhD}^{1}$, Katsunori Imai, MD, PhD $^{1}$, Hidetoshi Nitta, MD, $\mathbf{P h D}^{1}$, Akira Chikamoto, MD, $\mathrm{PhD}^{1}$, Toru Beppu, $\mathrm{MD}, \mathrm{PhD}^{1,2}$, and Hideo Baba, MD, $\mathrm{PhD}^{1}$

${ }^{1}$ Department of Gastroenterological Surgery, Graduate School of Life Sciences, Kumamoto University, Kumamoto, Japan;

${ }^{2}$ Department of Surgery, Yamaga City Medical Center, Kumamoto, Japan

This retrospective study (https://doi.org/10.1245/s1043 4-021-10706-7) demonstrated that histological liver inflammation may be a predictor of postoperative complications, early recurrence, and poor short- and long-term prognosis in 500 patients with hepatocellular carcinoma who underwent hepatectomy. Severe liver inflammation was associated with poor short- and long-term prognoses independent of cirrhosis. Controlling liver inflammation in the perioperative period may be essential to improving the prognosis of patients with HCC after hepatectomy.

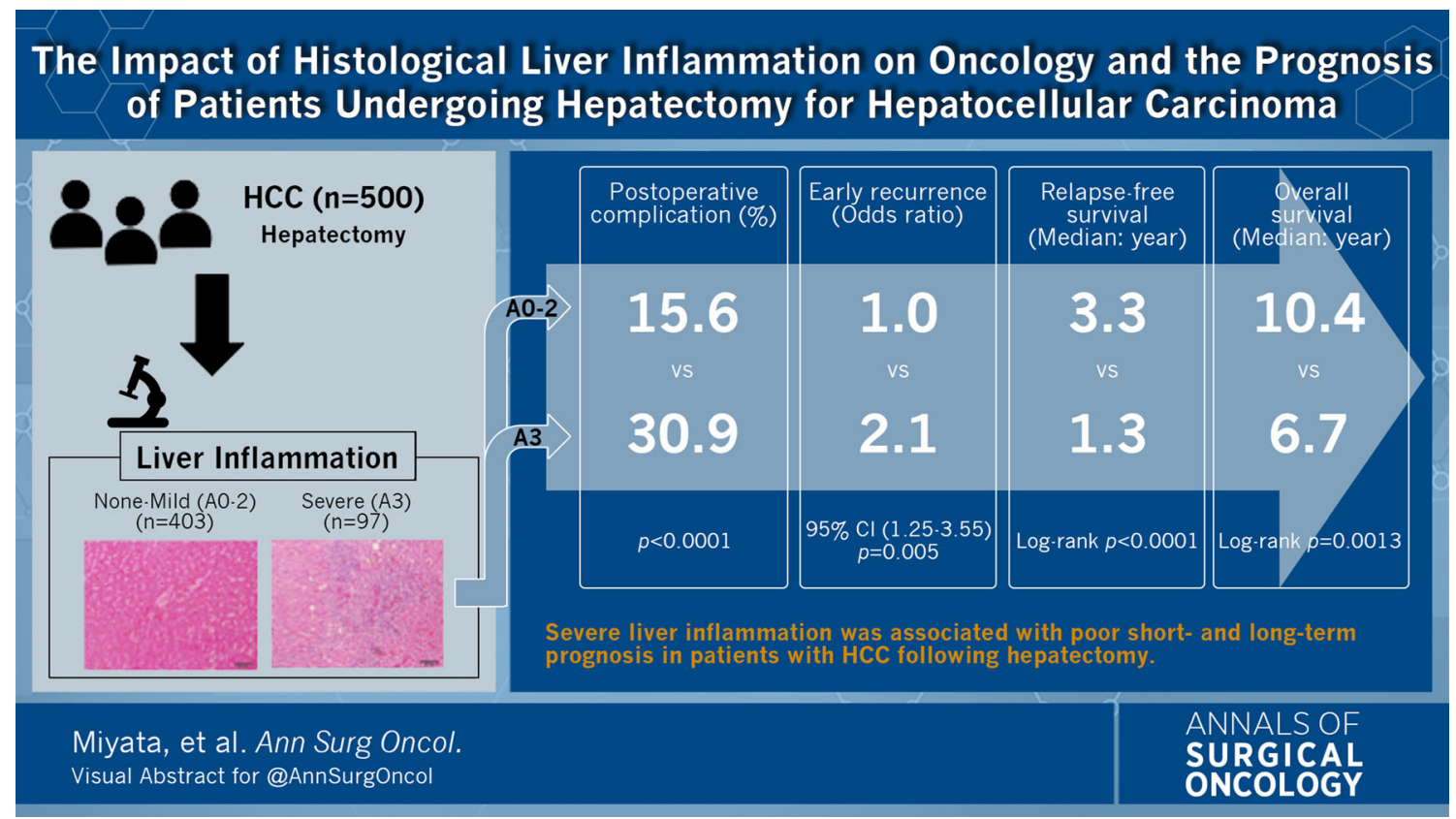

(C) Society of Surgical Oncology 2021

Published Online: 5 September 2021

H. Baba, MD, PhD

e-mail: hdobaba@kumamoto-u.ac.jp
DISCLOSURE None of the authors has any conflict of interest.

Publisher's Note Springer Nature remains neutral with regard to jurisdictional claims in published maps and institutional affiliations. 